\title{
Research on MAS-Based Supply Chain Resilience and Its Self-Organized Criticality
}

\author{
Liang Geng, ${ }^{1,2}$ Renbin Xiao, ${ }^{1}$ and Xing $\mathrm{Xu}^{3}$ \\ ${ }^{1}$ School of Automation, Huazhong University of Science and Technology, Wuhan 430074, China \\ ${ }^{2}$ School of Science, Hubei University of Technology, Wuhan 430068, China \\ ${ }^{3}$ School of Mechanical and Automotive Engineering, Zhejiang University of Science and Technology, Hangzhou 310023, China
}

Correspondence should be addressed to Renbin Xiao; rbxiao@hust.edu.cn

Received 11 April 2014; Revised 11 June 2014; Accepted 28 June 2014; Published 23 July 2014

Academic Editor: Weihua Liu

Copyright (C) 2014 Liang Geng et al. This is an open access article distributed under the Creative Commons Attribution License, which permits unrestricted use, distribution, and reproduction in any medium, provided the original work is properly cited.

Building resilient supply chain is an effective way to deal with uncertain risks. First, by analyzing the self-organization of supply chain, the supply chain resilience is described as a macroscopic property that generates from self-organizing behavior of each enterprise on the microlevel. Second, a MAS-based supply chain resilience model is established and its local fitness function, neighborhood structure, and interaction rules that are applicable to supply chain system are designed through viewing the enterprise as an agent. Finally, with the help of a case, we find that there is an agglomeration effect and a SOC characteristic in supply chain and the evolution of supply chain is controlled by parameters of MAS. Managers can control the supply chain within the resilient range and choose a good balance between interest and risk by controlling enterprises' behavior.

\section{Introduction}

Although the supply chain has been improved in efficiency during the globalization of economy, it has also become riskier. A great deal of research has been conducted on supply chain flexibility, robustness, and vulnerability in recent years. The risk in different aspects of the supply chain is nevertheless unresolved. In order to overcome the vulnerability, the supply chain should possess comprehensive advantages in robust and flexible strategies. A concept of establishing a resilient supply chain is proposed. Supply chain resilience can be regarded as a comprehensive integration of the supply chain flexibility, robustness, and vulnerability.

Supply chain flexibility is a concept that focuses on the capability to adapt to the external changes. And it also reflects the adaptability of the system, which is a "change responding to change" strategy. Compared with the supply chain network resilience, the definition of flexibility is relatively narrower, which mainly refers to the ability to respond to the changes in customers' demand. This depends on the coordination of information flow, logistics, and capital flow between the upstream and downstream members of the supply chain.
The supply chain robustness is the ability to maintain operational function when the system is subject to uncertain interference from the internal operations and external events, which characterizes the robustness of the system, and is a rigid "maintaining the status quo" strategy [1]. Although the supply chain robustness cannot adapt, the supply chain flexibility can do it. This adaptive capacity refers to the ability to quickly restore its original state or a state that benefits the supply chain operations when an interruption occurs. In other words, robustness is the ability of anti-impact, while resilience is the ability to quickly recover from the impact.

Supply chain vulnerability reflects the maximum impact that the supply chain can resist under network interruption, which means the maximum deviation from the normal performance after an interruption occurs. The duration of interruption is not a significant factor of vulnerability, while the maximum negative impact of the interruption is significant. Vulnerability is one of the aspects that measure resilience.

The supply chain flexibility strategy and robustness strategy have their own strengths as well as limitations. Supply 
chain resilience, which contains adaptability without losing robustness, puts more emphasis on recovery capability.

The reason why supply chain has such strong competitive ability is owing to the fact that the supply chain is a virtual organization which has self-organizing ability and consists of enterprises with different functions and different types. In actual operation, every enterprise is an organization that possesses independent power to make decisions, and any enterprise cannot fully control the behavior of other enterprises. Besides, there is no internal centralized control within supply chain system. Each enterprise follows certain rules, fulfills its duties, and mutually coordinates with each other, and the system automatically forms an ordered structure, which reflects the self-organizing ability of the supply chain. In a word, the microlevel self-organization of supply chain is the root of reflecting the macrolevel supply chain resilience.

The way to make in-depth analysis of supply chain resilience is to start from microlevel self-organization of the supply chain and adopt bottom-up modeling method to study the interaction rules of each individual in supply chain system, which generates macrolevel supply chain resilience. From the system point of view, this paper studies the root of generating supply chain resilience and its properties. Through taking each enterprise as an agent and regarding supply chain local relationships as the environment, it builds multiagent systems that are similar to physical system and designs the unique local fitness function, neighborhood structure, and mutual interaction rules that supply chain owns. Then, it uses local information to guide the interactions between the agents as well as between the agents and the environment by agents' self-organizing ability, which ultimately generates supply chain resilience.

\section{Literature Review}

Resilience was first introduced by Holling [2], who proposed that "resilience determines the persistence of relationships within a system and is a measure of the ability of these systems to persist and absorb changes of state variables, driving variables, and parameters." Since then, the concept of resilience has been studied in many disciplines as shown in Table 1.

Resilience of supply chain was defined as the ability to return to its original state or an even better state after the disruptive event. Resilience of supply chain encompasses conducting preparation, response, and recovery activities for a disaster event.

There are some quantitative studies which attempt to create a framework for assessing supply chain resilience performance (see Table 2).

These literatures studied supply chain resilience from certain aspects. But there is no literature on the root of supply chain resilience and its characteristic, which is what we want to study.

\section{Generation of Supply Chain Resilience}

3.1. Supply Chain Resilience. Supply chain is an open system. As an economic system, supply chain system is essentially the
TABLE 1: Resilience studies in many disciplines.

\begin{tabular}{lc}
\hline Authors & Disciplines \\
\hline Folke et al. [3] & Ecology \\
Adger [4] & Sociology \\
Bonanno [5] & Psychology \\
Callaway et al. [6] & Network theory \\
Starr et al. [7] & Risk management \\
Sheffi [8] & Supply chain \\
\hline
\end{tabular}

result of communicating and integrating resources and ability between enterprises or between enterprises and the external environment. In the supply chain system, the distribution of resources, such as capital, technology, and brand, is different and unbalanced. Besides, the ownership and acquisition of resources, the obtaining of synergy theory and synergy results, the distribution of the interests between allies, and so on are also unbalanced. Competitive environment makes collaborative organizing activities of the supply chain members far from equilibrium. The nonlinear interaction of supply chain system determines its self-organizing evolution. Nonlinear interaction leads to the existence of both cooperation and competition between all members, and fluctuation of the individual is able to scale into the overall behavior. Due to random fluctuations, supply chain system becomes orderly and even forms new structure. For example, the consequences of information distortion and bullwhip effect lead to the fluctuations of manufacturers' state, and some minor changes in market factors may accumulate to fierce fluctuation of manufacturers' state, which may even make the whole system collapse. Thus, supply chain is a self-organizing system. Only when supply chain is in an open environment can it input the material, energy, and information and reduce the entropy of the system. Furthermore, only when supply chain stays far from equilibrium can it form intrasystem fluctuations and promote its spontaneous activity under nonlinear interactions. Such self-organizing ability gives the supply chain strong innovation ability and adaptability, which is the root of its strong competition.

On the microlevel, each enterprise in the supply chain is deemed as an agent. The agent can change with the environment and self-organize to make decision. Every time the environment factors change, it prompts each agent in the supply chain to change its own executing ability under the action of self-organizing ability and further changes its status in the supply chain. Such process goes on continuously, which forms the evolution process of supply chain system. The supply chain evolution process is in fact a self-organizing process, which generates supply chain resilience. In a self-organizing system, it forms the macroform or order from bottom to top through the "local rules" of each individual behavior, such property of the whole while part doesn't possess, is called "emergence." Supply chain resilience generates from selforganizing behavior of each member, as shown in Figure 1.

On the macrolevel, resilience management ability analyzes the effect on resilience from the following aspects as a whole: adaptation and coordination between node members, 
TABLE 2: Quantitative studies on supply chain resilience.

\begin{tabular}{|c|c|c|}
\hline Authors & Methods & Main works and findings \\
\hline Priya Datta et al. [9] & $\begin{array}{l}\text { Agent-based computational } \\
\text { modelling }\end{array}$ & $\begin{array}{l}\text { This literature studied complex multiproduct and multicountry } \\
\text { supply chain subject to demand variability and production and } \\
\text { distribution capacity constraints, which aimed to improve operational } \\
\text { resilience. }\end{array}$ \\
\hline Ratick et al. [10] & Linear programming & $\begin{array}{l}\text { The literature used set cover location modeling to show that it is } \\
\text { important to take into account potential exposure of facilities when } \\
\text { designing supply chains. }\end{array}$ \\
\hline Colicchia et al. [11] & $\begin{array}{l}\text { Simulation applied to real } \\
\text { scenario }\end{array}$ & $\begin{array}{l}\text { This literature identified a set of approaches to manage risks to } \\
\text { enhance supply chain resilience. Mitigation strategies do not } \\
\text { influence lead-time variability but can reduce lead-time average, } \\
\text { which will lead to resilience. }\end{array}$ \\
\hline Zhao et al. [12] & $\begin{array}{l}\text { The simulation analysis of } \\
\text { military security network }\end{array}$ & $\begin{array}{l}\text { This literature analyzed resilience of supply network topology } \\
\text { structure under random attacks and attempted attacks from the } \\
\text { aspects of availability, connectivity, accessibility, and so forth. }\end{array}$ \\
\hline Geng et al. [13] & $\begin{array}{l}\text { The simulation analysis of } \\
\text { cluster supply chain }\end{array}$ & $\begin{array}{l}\text { This literature analyzed dynamic evolution process based on } \\
\text { cascading effect mode when cluster supply chain failure happens, } \\
\text { which helped to illustrate that the root of vulnerability lies in } \\
\text { cascading failure, while self-organization is the key to resilient } \\
\text { recovery. }\end{array}$ \\
\hline Pettit et al. [14] & Questionnaire survey & $\begin{array}{l}\text { This literature developed a measurement tool titled the Supply Chain } \\
\text { Resilience Assessment and Management. Critical linkages are } \\
\text { uncovered between the inherent vulnerability factors and controllable } \\
\text { capability factors. }\end{array}$ \\
\hline Francis and Bekera [15] & $\begin{array}{l}\text { The simulation analysis of } \\
\text { electric power network }\end{array}$ & $\begin{array}{l}\text { This literature proposed a framework which is focused on the } \\
\text { achievement of three resilience capacities: adaptive capacity, } \\
\text { absorptive capacity, and recoverability. }\end{array}$ \\
\hline
\end{tabular}

\begin{tabular}{|c|c|c|}
\hline Resilience & $>_{\text {Supply chain }}$ & Supply chain \\
\hline management ability & ability & resilience effect \\
\hline
\end{tabular}

The macrodescription of supply chain resilience

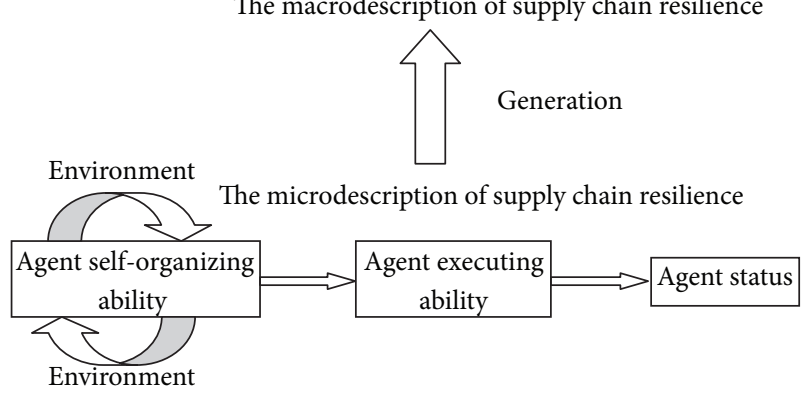

FIGURE 1: Micro- and macrodescription of supply chain resilience.

prediction of future events, recovery situation from disaster, and so forth. Reflected into the microlevel, resilience management ability is the self-organizing ability of each agent in supply network. Supply chain ability is an important ability that maintains the normal operation of entire supply chain network, which is the executing ability of each agent in supply network when reflected into the microlevel. Reflected into the microlevel, supply chain resilience effect is each agent's status in the supply network, which represents each enterprise's activity ability and network status, and is represented by its kinetic energy and potential energy. Micro- and macrocontrast of supply chain are shown in Table 3.
Resilience management ability has positive influence on supply chain resilience. When supply chain risk happens, some node members may not be able to survive together with the other members in the supply chain. At this time, it needs some enterprises with similar resources to join in; if the new enterprise can quickly integrate into the supply chain, then it can improve customer satisfaction and business performance of the supply chain, which means that it can improve supply chain resilience. If enterprises can predict future events well, they can take corresponding prevention measures to reduce the effects that risk brings, and even if the risk happens, they can take positive measures to restore normal state of supply chain and improve supply chain resilience. And if the recovery ability of node members is strong enough, the supply chain can meet normal operation conditions of enterprises as soon as possible and decrease stock-out rate and then improve supply chain network resilience. In addition, after the risk happens, if enterprises can coordinate well, they can ride out the storm together, maintain the normal operation of supply chain, improve customer satisfaction, ensure enterprise performance, and improve supply chain resilience.

Supply chain ability has positive impact on supply chain resilience and resilience management ability. The stronger the supply chain ability is, the stronger the ability of supply chain node enterprises to deal with various emergencies is. Even if supply chain risk happens, supply chain can recover quickly, and supply chain resilience will be strengthened. Thus it can be seen that supply chain ability is a key factor that 
TABLE 3: Micro- and macrocontrast of supply chain.

\begin{tabular}{|c|c|c|c|}
\hline \multicolumn{2}{|c|}{ Macrocontrast } & \multicolumn{2}{|r|}{ Microcontrast } \\
\hline $\begin{array}{l}\text { Resilience } \\
\text { management ability }\end{array}$ & $\begin{array}{l}\text { Adaptability, } \\
\text { predictive ability, } \\
\text { recovery ability, } \\
\text { coordinating ability }\end{array}$ & $\begin{array}{l}\text { Agent self-organizing } \\
\text { ability }\end{array}$ & $\begin{array}{l}\text { Learn from each other, exchange } \\
\text { experiences, communicate and coordinate, } \\
\text { share risk, get warning information as early } \\
\text { as possible, reduce unnecessary loss, and } \\
\text { recover function quickly. }\end{array}$ \\
\hline Supply chain ability & $\begin{array}{l}\text { Information management ability, } \\
\text { logistics management ability, } \\
\text { resource support ability, } \\
\text { target combination ability, } \\
\text { fund procurement ability, } \\
\text { risk management ability, } \\
\text { reconstruction transformation } \\
\text { ability, } \\
\text { study and absorptive ability }\end{array}$ & $\begin{array}{l}\text { Agent executing } \\
\text { capability }\end{array}$ & $\begin{array}{l}\text { Collect, analyze, and sort the information } \\
\text { and finally obtain effective information. } \\
\text { Deal with logistics facilities establishment } \\
\text { and location and provide optimized logistics } \\
\text { protection. Find node members that fit for } \\
\text { their own development and make effective } \\
\text { combination to reach the company target. } \\
\text { Complete fund procurement and maintain } \\
\text { the normal operation of enterprises after the } \\
\text { occurrence of risk. Find new resources to } \\
\text { meet the changing market. Improve the } \\
\text { defects in the supply chain and build a new } \\
\text { supply chain network. }\end{array}$ \\
\hline $\begin{array}{l}\text { Supply chain } \\
\text { resilience effect }\end{array}$ & $\begin{array}{l}\text { Wavy curve } \\
\text { asymptotically stable }\end{array}$ & Agent status & Activity ability, network status. \\
\hline
\end{tabular}

influences supply chain resilience, and flexible use of various supply chain abilities can improve the ability of enterprises to face risks, improve supply chain resilience, and then improve enterprise performance. Under the effect of resilience management ability that formed by self-organization, supply chain ability can manage various risks effectively and help enterprises survive through a variety of difficulties [16].

Supply chain resilience effect is an asymptotically stable wave curve. It changes with time, showing the process that successively reflects response delay, reflects destruction spread, reflects destruction recovery, and eventually achieves asymptotically stable state. Such description of supply chain resilience effect not only clearly lays out the self-organizing evolution of supply chain resilience that changes with the time, but also meets several major features that supply network resilience should have, such as self-recovery, antidisruption, and active response. Besides, it can evaluate absorption ability, adaptability, and recovery ability of the supply chain. For details, please see our previous study in [13].

Definition of Resilience. The supply chain resilience is defined as follows: when dealing with unexpected interrupts, supply chain system restores a new stable state through microconstant evolution of enterprises' self-organizing ability; such emergence on the macrolevel is shown as supply chain resilience. Supply chain system with resilience can eliminate the influence brought by fluctuations, release energy, and then slow down the occurrence of large-scale collapse on the whole.

3.2. Self-Organized Criticality of Supply Chain Resilience. An important concept related to the self-organization is selforganized criticality (SOC) [17-19]. The SOC theory refers to an open and dynamic complex system that is far from equilibrium state and consists of multiple cells, which can evolve to a critical state through self-organizing process.
When such system stays in the critical state, a small local disturbance may be amplified by mechanism similar to "domino effect," and the effect may be extended to the entire system, forming a large avalanche. System in the critical state will bring about "avalanche" events of various sizes, and both the avalanche's time dimension and its space dimension obey power-law distribution. The power-law distribution is an important characteristic of self-organized criticality, which also owns scale-free property, openness, robustness, and other characteristics.

Some literatures show that supply chain network has scale-free, high integration, and other characteristics. The average outgoing and incoming degree distribution of supply chain network under steady state obeyed power-law distribution [20-22].

This paper argues that supply chain resilience possesses self-organized criticality. The process that supply chain evolves towards the critical state is not affected by any external factors. Owing to the dynamic interactions between individual elements in the system, the critical state can be set up and such critical state is self-organizing. Within the critical point of supply chain resilience, core enterprises can control the changes of system external parameters at proper time based on understanding and grasping the operation mechanism and laws, so they can constrain system's operation process, making the system produce small internal fluctuations. Such gradually varied internal fluctuation process of the system could eliminate conflicts within the system, making the system stay in balance, which means that the system possesses resilience. At the critical point of supply chain resilience, it may be amplified into a huge fluctuation through nonlinear interactions and cascading effects within the system, leading to a rapid collapse after the system loses its balance.

This paper will expound such a view as follows. The microlevel interactions between enterprises in the supply 
chain result in the macrolevel self-organized criticality generation of supply chain resilience. If the supply chain is within the critical value, small disturbance will only lead to tiny changes and system will not meet any great disaster. On the contrary, if the environment variables reach the critical value, small disturbance may lead to various scales of avalanche.

\section{Supply Chain Resilience Control Model Based on MAS}

The paper is intended to build supply chain MAS system and interpret and evaluate supply network resilience through self-organizing ability of its intelligent agents. In this section, we will define the agent, environment, local fitness function, interactive strategy, and reaction behavior between the agents of MAS, build the MAS system of supply network, put forward supply network resilience index, and study the characteristics of resilient generation from the point of selforganization.

4.1. Basic Concepts of MAS. An agent is able to survive and take part in activities in the environment, which can sense its local environment and has certain goal as well as state variable of reaction behavior. MAS system is a system that achieves a certain goal by the interactions and effects between many internal agents. MAS system consists of computing entities that possess autonomy, reactivity, initiative, and social attributes. By microscopic or local (i.e., agents and the interactions between them) behavior or mechanism, MAS desires to obtain necessary macroglobal (i.e., the entire multiagent system) function [23, 24].

The definition of MAS system is as follows.

Definition (MAS system). An agent system is a system that contains the following elements:

(1) the environment $E$, in which the agents survive and conduct activities;

(2) a set of agents, $A=\left(a_{1}, a_{2}, \ldots, a_{n}\right)$;

(3) a set of reaction rules, which controls the interaction behavior between agents as well as between agents and the environment and is the law of the agent society.

Supply chain individuals own self-organizing properties, including intelligence and adaptability, follow certain rules, and adjust their states and behavior according to the environment and received information, making the system show a higher level of order as a whole. In other words, the supply chain is a MAS system. Supply chain system is based on the idea of decentralized control and each individual makes corresponding decision-making behavior in the current neighborhood according to the local information and local fitness function. The overall behavior of the supply chain generates through competition, cooperation, and other local behaviors between individuals.

The study on resilient self-organizing emergence of supply chain MAS is faced with 4 key problems as follows [25].
(1) The first problem is how to reasonably map the supply chain system into a MAS system, namely, the definition of the agent.

(2) The second problem is how to define the local fitness function. The local fitness function is based on the idea of distributed control, using limited local information to evaluate the state of a single agent and guide the overall evolution. Although the definition of local fitness function is not unique, reasonable local fitness function is the key to the effect of self-organization emergence.

(3) The third problem is how to define the neighborhood. The definition of neighborhood is a very important concept for optimizing the neighborhood, which guides how to generate a new state from the current state. Furthermore, how to choose a reasonable neighborhood structure is an important factor to the selforganizing optimization.

(4) The fourth problem is how to define the interaction rules between agents. MAS system achieves overall self-organization evolution through competition and cooperation between the agents. The reasonable and effective interaction rules between the agents can quickly lead the system to generate stable structure.

4.2. Mapping the Supply Network into MAS. To map the supply network into MAS system, now we define the following concepts.

4.2.1. Agent. Take each enterprise in the supply chain as an agent [26] and the specific descriptions of the agents in supply chain MAS are shown in Figure 2.

A supply network system that consists of $N$ agents is given and represented as $S=\langle X, P, V, A\rangle$, where $X=$ $\left(x_{1}, x_{2}, \ldots, x_{i}, \ldots, x_{N}\right), x_{i} \in R^{n}$, is the position vector of agent $i$, which represents the status of this member in supply chain; $P=\left\{c_{1}, c_{2}, c_{3}, c_{4}, c_{5}, d, r, A_{\max }, V_{\max }\right\}$ is the control parameter set of the agents; $V=\left(v_{1}, v_{2}, \ldots, v_{i}, \ldots, v_{N}\right), v_{i} \in R^{n}$, is the velocity vector of agent $i$, which represents the executing ability of the member; and $A=\left(a_{1}, a_{2}, \ldots, a_{i}, \ldots, a_{N}\right)$, $a_{i} \in R^{n}$, is the acceleration vector, which represents the self-organizing ability of the member. In other words, we assume that each member owns such attributes as selforganizing ability, executing ability, and network status, as shown in Figure 3 . The executing ability of a member is its self-organizing ability multiplied by time, and the status of this member is its executing ability multiplied by time. The motion of an agent is controlled by the following equation:

$$
\dot{x}_{i}=v_{i}, \quad \dot{v}_{i}=a_{i} .
$$

4.2.2. Local Fitness Function. Assume that the decision of each enterprise in supply chain is determined by the enterprise status $V_{1}$ in the neighborhood, the core enterprise of the overall supply chain has status $V_{2}$, the executing ability of the enterprise within neighborhood is $V_{3}$, the core enterprise within the neighborhood has status $V_{4}$, and random perturbation is $V_{5}$. Affected by local influence, self-organizing 


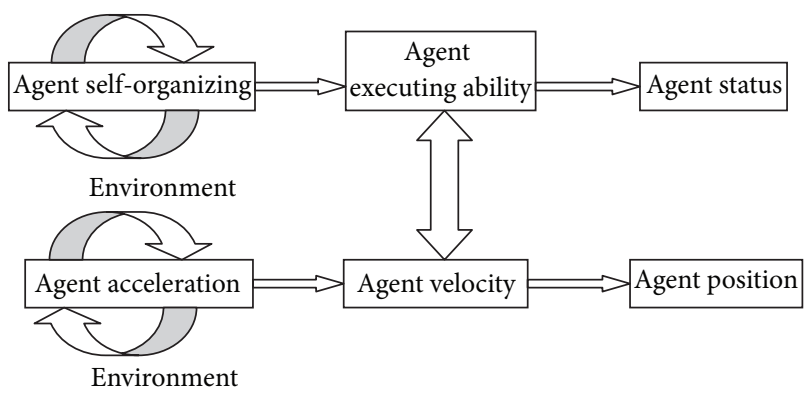

FIGURE 2: MAS mapping of supply chain.

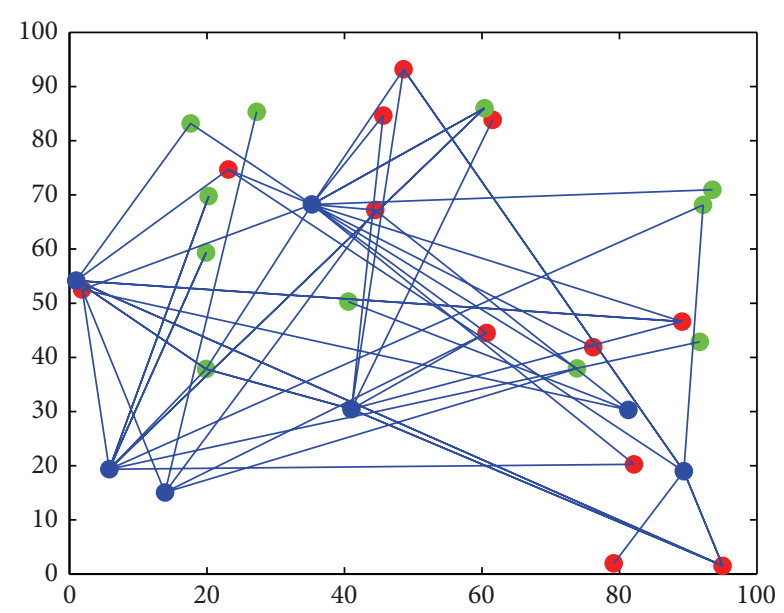

FIGURE 3: The initial supply network of FAW Xiali.

ability and executing ability of each member in the supply chain are changing with the time, and self-organizing ability causes changes in executing ability. In the model, local fitness function of the agent represents the agent's self-organizing ability at each time step, which means the instantaneous acceleration vector of the agent.

The local fitness function, namely, the calculating formula of instantaneous acceleration, is as follows:

$$
\begin{gathered}
V=c_{1} V_{1}(d)+c_{2} V_{2}+c_{3} V_{3}+c_{4} V_{4}+c_{5} V_{5}, \\
A=A_{\max } \frac{V}{|V|} .
\end{gathered}
$$

$V_{1}$ is a vector that points to the neighbors within a distance of $d ; V_{2}$ is a vector describing the center of the simulated world; $V_{3}$ is the average of the neighbors' velocities; $V_{4}$ is a vector that points toward the center of gravity of the neighbors; $V_{5}$ is a random unit-length vector; $V$ is the summation of behavioral tendencies with weights; $A$ is an agent's instant acceleration vector at each time step $(|A|<$ $\left.A_{\max }\right) ; A_{\max }$ is the maximum acceleration of an agent; $V_{\max }$ is the maximum velocity of an agent; $c_{1}-c_{5}$ are the weights of vectors $V_{1}-V_{5} ; d$ is the desired distance that an agent tries to maintain with its neighbors; the combination of $c_{1}$ and parameter $d$ determines the relaxation degree of model shape; $c_{2}$ is used to control the motion range of all agents in the analog world; $c_{3}$ represents the consistency degree that makes certain individual keep the same velocity with other individuals in its neighborhood; $c_{4}$ indicates the distance degree that makes certain individual keep away from other individuals in its neighborhood; and $c_{5}$ is used to control the arbitrary degree of individual's acceleration change.

4.2.3. Environment. The agent in supply chain mainly selforganizes and adjusts its behavior according to the neighbors' behavior. An agent that relates to any other agent must exist within certain range, and the relationship between agents can be divided into two states: cooperation and noncooperation, which is shown as attraction and rejection behavior. Define the neighborhood of agent $i$ as follows:

$$
\mathrm{NEB}_{i}=\left\{x_{j} \mid\left\|x_{i}-x_{j}\right\| \leq d, i \neq j ; i, j=1,2, \ldots, N\right\},
$$

where $\left\|x_{i}-x_{j}\right\|$ is Euclidean distance and $d$ is neighborhood radius, which is the optimal distance between every two agents.

Define the rejection region of agent $i$ as follows:

$$
\operatorname{REP}_{i}=\left\{x_{j} \mid\left\|x_{i}-x_{j}\right\| \leq r, i \neq j ; i, j=1,2, \ldots, N\right\},
$$

where $r$ is the rejection distance, which is the maximum operating distance of the rejection function, $r \leq d$. If the distance between two agents is less than $r$, then the rejection occurs.

4.2.4. Response Rules. In this paper, we divide the neighborhood range according to the distance between each agent and its neighbor agents. An agent establishes or disconnects the interaction between it and other agents within the neighborhood, which makes the local topology structure of agents in the system change, leading to the entire system topology evolution.

Response rules are as follows. The member that enters into the neighborhood from somewhere outside the neighborhood establishes new contacts. And the members within rejection region have competitive relationship and repulsive force towards other agents within rejection region, while the members within neighborhood have cooperative relationship and attractive force towards other agents within the neighborhood. By the local fitness function, we can obtain new selforganizing ability and executing ability of each member and then get the new network status.

4.3. The Resilient Index of Supply Chain MAS. Supply chain MAS is a self-organizing system, and its resilience generates from the microlevel and is revealed in macrolevel. The concept of energy in system dynamics can be an effective interpretation of the relationship between behavior and internal mechanism. Positive and negative feedback mechanisms are formed between every two agents, which is shown as the transmission of system internal energy. Therefore, we can show the influence of dynamic process on overall system resilience through quantifying system internal energy.

Assume that each supply chain member is an agent with resilience; then we can determine whether the relationship between it and other members is strengthened or weakened 
according to the environment, such as order quantity. The relation change between two agents can be seen as elastic force of mutual attraction or mutual repulsion, and the elastic force causes the movement of the agent, which leads to changes of the agent status in the entire supply chain. For example, certain enterprise will rise in the competition and become the core business, and core enterprise may gradually lose dominance. Take the agent status in the supply network as the elastic potential energy and the agent activity in the supply network as the elastic kinetic energy, which together constitute the resilient system of supply chain.

$U_{i}(t)$ and $E_{i}(t)$ are used to, respectively, represent the potential energy and kinetic energy of agent $i$, and $U_{i}(t)$ is the relative potential energy of the agent compared to MAS center; $U_{i}(t)=\left\|\operatorname{pos}_{i}-\overline{\operatorname{pos}}\right\|^{2}$. Kinetic energy $E_{i}(t)$ is the relative kinetic energy of the agent compared to MAS center; $E_{i}(t)=\left\|v_{i}-\bar{v}\right\|^{2}$.

The resilient index of supply chain MAS is

$$
Q(t)=\sum_{i=1}^{N}\left(U_{i}(t)+E_{i}(t)\right) \text {. }
$$

\subsection{Algorithm Implementation}

Step 1. Initialize the state of each agent in supply chain and corresponding weights of the objects.

Step 2. With regard to the current state, do the following.

(1) Calculate the neighborhood of current scheme and judge whether it belongs to neighbors.

Because each agent only communicates with adjacent agents and local environment, we need to determine whether the distance between each agent and other agents is within the given value of the neighbor; namely, we need to judge whether the two agents are neighbors or not. And this is the basis of calculating subsequent variables. If the distance between two agents is less than the value of neighbor, then the two agents are neighbors and their behaviors affect each other. Otherwise, the two agents do not affect each other. Given that the distance value between two agents is $d(i, j)$, the judge is as follows:

$$
\text { if } d \leq \text { neighbor, then } i \text { and } j \text { are neighbors. }
$$

(2) Calculate the values of variables $V_{1}-V_{5}$.

$V_{1}$ is the average vector of certain agent pointing to all other agents within a distance of $d$, named as Spacing $U$. If two agents $i$ and $j$ are neighbors but their distance is less than a given value, then the two will produce repulsion and adjust the vector $V_{1}$ as follows:

$$
\begin{aligned}
& \operatorname{Spacing} U(i,:)=\operatorname{Spacing} U(I,:)+[\operatorname{abs}(x(i)- \\
& x(j)) \operatorname{abs}(y(i)-y(j))] .
\end{aligned}
$$

$V_{2}$ is a vector pointing to the center of analog world and its name is decided by the center of analog world, named as $W$ center $U$, where $i \neq j$ and $N$ is the number of agents. Consider the following:

$$
\begin{aligned}
& W \text { center } U(i,:)=[W \text { center } U(i,:)+x(j) W \operatorname{center} U(i, \\
& :)+y(j)] \\
& W \text { center } U(i,:)=W \operatorname{center} U(i,:) / N
\end{aligned}
$$

Moreover, we need to limit the range of the vector, in order to make entire motions of the system within the range, and adjust the vector as follows:

$$
\begin{aligned}
& \text { If } \mid W \text { center } U(i,:) \mid>\text { bound, } \\
& W \text { center } U(i,:)=[W \text { center } U(i,:)-x(j) W \operatorname{center} U(i, \\
& :)-y(j)] .
\end{aligned}
$$

$V_{3}$ is the average speed vector of all agents that is adjacent to certain agent, named as Velocity $U$, and its value is determined by the speed of the agent and its neighbors:

$$
\begin{aligned}
& \operatorname{Velocity} U(i,:)=\operatorname{Velocity} U(i,:)+\operatorname{Velocity} U(j,:), \\
& \operatorname{Velocity} U(i,:)=\operatorname{Velocity} U(i,:) / \text { number(neighbor). }
\end{aligned}
$$

$V_{4}$ is a vector of certain agent pointing to the center of all of its adjacent agents, which is determined by the average vector of the agent and its adjacent agents, named as CenterU. Its value is determined by the speed of the agent and its neighbors:

$$
\begin{aligned}
& \text { Center } U(i,:)=[\operatorname{Center} U(i, 1)+x(j) \operatorname{Center} U(j,:)+ \\
& y(j)], \\
& \text { Center } U(i,:)=\operatorname{Center} U(i,:) / \text { number(neighbor). }
\end{aligned}
$$

$V_{5}$ is a vector of random unit length, named as Wander $U$, the initial value of which is randomly given as follows:

$$
\text { Wander } U(i,:)=2 * \operatorname{rand}(1,2) .
$$

(3) Calculate the local fitness value of each agent according to local fitness function, which means the calculation of agent's acceleration.

(4) Guide the interactions between all agents according to local fitness function, which means the calculation of agent's new position.

The interactions between all agents make the system evolve from initial interrupts to the equilibrium state of each node. Under the new obtained equilibrium state, change the agent state according to system local energy information, which makes the system achieve a more stable equilibrium state again and optimize the system resilience.

(5) Return the current value of system resilience.

Step 3. Repeat Step 2 until termination.

\section{Case Simulation and Analysis}

Take the Tianjin FAW Xiali Automobile Group's supply chain as a prototype for simulation. According to the transactions in 2011, we extract and compare FAW Xiali's supply data of recent years and then select the enterprises that make transactions with Tianjin FAW Group of more than 500,000 yuan as the nodes to constitute the supply chain we study, which includes 12 major suppliers and 7 principal subsidiaries as well as 11 major vendors of Tianjin FAW Group [27]. The initial network is shown in Figure 3.

5.1. Evolution Characteristics of Supply Chain. We select 5 sets of parameters to regulate the behavior of each supply chain member and simulate the process of supply chain evolution, 
TABLE 4: The simulation coefficient.

\begin{tabular}{lcccccccc}
\hline Number & $c_{1}$ & $c_{2}$ & $c_{3}$ & $c_{4}$ & $c_{5}$ & $V_{\max }$ & $A_{\max }$ & $d$ \\
\hline 1 & 5 & 8 & 7 & 8 & 5 & 13 & 38 & 0.14 \\
2 & 6 & 15 & 10 & 8 & 7 & 5 & 38 & 0.14 \\
3 & 6 & 9 & 1 & 5 & 8 & 36 & 11 & 0.59 \\
4 & 3 & 5 & 7 & 7 & 4 & 13 & 37 & 0.40 \\
5 & 3 & 5 & 7 & 7 & 4 & 13 & 37 & 0.10 \\
\hline
\end{tabular}

as shown in Table 4 . In particular, the network diagram of part time period in evolution process of number 1 is selected to represent the evolution process of supply chain, as shown in Figure 4. In Figure 4, vertical and horizontal coordinates represent agent's position in MAS, which reflects enterprise status in the supply chain. As we can see from Figure 4, each agent's vertical and horizontal coordinates' value gradually increases, which means that the ability of each enterprise in supply chain is constantly increasing. And the distance between all agents is smaller and smaller, which means that the cooperation between enterprises is closer and closer. The supply chain shows a combined effect.

Figures 5, 6, 7, and 8, respectively, correspond to the evolution results of the 4 sets of parameters from number 2 to number 5 . These evolution results all reflect the combined effect of supply chain and the parameters have a certain impact on it. We find that the parameter of $V_{\max }$ directly influences the speed of combined effect. Comparing number 1 with number 2, when we decrease the value of $V_{\max }$ from 13 to 5 and keep the other parameters unchanged, the speed of combined effect is significantly faster. Because the enterprise executive ability becomes stronger, mutual cooperation is more efficient. In addition, the parameter $d$ also has a direct impact on the speed of combined effect. Comparing number 3 with number 5 , the value of $d$ is larger in number 3 , which means that each enterprise has larger neighbor range and can cooperate with more enterprises, leading to more mutual cooperation and faster combined effect speed, while the value of $d$ in number 5 is smaller and the situation is just the opposite.

Supply chain vulnerability is caused by cascading failures, while the combined effect happens to be the hindrance of cascading failures. Therefore, the combined effect is a factor that shows supply chain resilience.

The evolution of supply chain lies in affecting and constraining mutual behavior through interconnections and interactions between individuals. Clustering coefficient can be used to express connectivity, as a quantitative indicator of supply chain MAS connectivity factor. The entire network clustering coefficient $C$ is the average of clustering coefficient $C_{i}$ for each node $i$. Consider the following:

$$
C_{i}=\frac{2 E_{i}}{\left[k_{i}\left(k_{i}-1\right)\right]} .
$$

Rate of information flow is established based on the connectability of individuals. The information flow can be shown through measuring the connection path length between individuals. We choose the average path length $L$ as a quantitative indicator of supply chain MAS internal information flow. Consider the following:

$$
L=\frac{2}{N(N-1)} \sum_{i=1}^{N} \sum_{j=i+1}^{N} d_{i j}
$$

Figure 9 shows the clustering coefficient (red) and the average path length (green) of supply chain evolution in number 1 . The clustering coefficient keeps rising, indicating that individual connectivity continuously strengthen, which gradually generates system resilience. When the clustering coefficient is 1 , it indicates that all agents are within other agents neighborhood and connectivity is optimal. The average path length keeps decreasing, indicating that the interactions of individual information change from indirect process to direct process. With the communication constantly decreasing, local rate of information flow is enhanced. When the average path length is 1 , the system has the best overall interactivity. The same characteristics of the two indexes are also shown in the data from number 2 to number 5 .

As the above characteristics, the degree of homogeneity in the supply chain enterprise is higher and higher. Such a system can resist well the expected danger, but in the face of some unexpected threat it becomes extremely fragile. Therefore, the supply chain is a robust-yet-fragile system.

5.2. Resilience Analysis of Supply Chain. The average acceleration vector, position center, and average velocity vector are represented as $\bar{a}, \bar{x}, \bar{v}$, respectively, and the calculation is as follows:

$$
\bar{a}=\frac{1}{N} \sum_{i=1}^{N} a_{i}, \quad \bar{x}=\frac{1}{N} \sum_{i=1}^{N} x_{i}, \quad \bar{v}=\frac{1}{N} \sum_{i=1}^{N} v_{i} .
$$

The neighborhood center of agent $i$ and the average velocity vector of all agents within its neighborhood are represented as $\bar{x}_{i}^{*}$ and $\bar{v}_{i}^{*}$, respectively, and the calculation is as follows:

$$
\bar{x}_{i}^{*}=\frac{1}{M_{i}} \sum_{j=1}^{M_{i}} x_{j}, \quad \bar{v}_{i}^{*}=\frac{1}{M_{i}} \sum_{j=1}^{M_{i}} v_{j},
$$

where $M_{i}$ is the number of agents within the neighborhood of agent $i$. Consider the following:

$$
\begin{gathered}
Q(t)=\frac{1}{2} \sum_{i=1}^{N}\left(U_{i}(t)+E_{i}(t)\right), \\
E_{i}(t)=c_{3}\left\|v_{i}-\bar{v}\right\|^{2}, \\
U_{i}(t)=c_{1}\left\|x_{i}-\bar{x}_{i}^{*}\right\|^{2}+c_{2}\left\|x_{i}-\bar{x}\right\|^{2}+\sum_{j=1, j \neq i} c_{4} \psi\left(\left\|x_{i}-x_{j}\right\|\right) .
\end{gathered}
$$




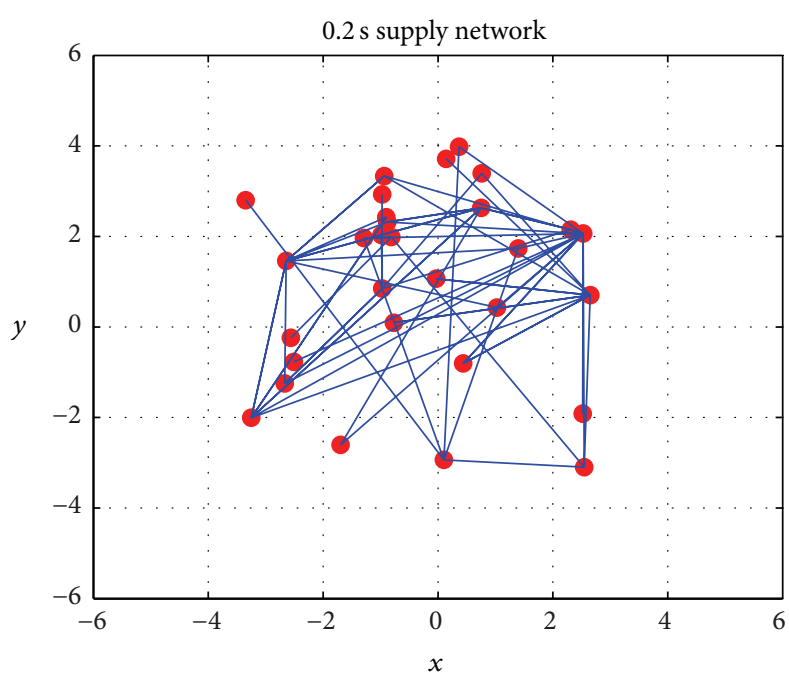

(a)

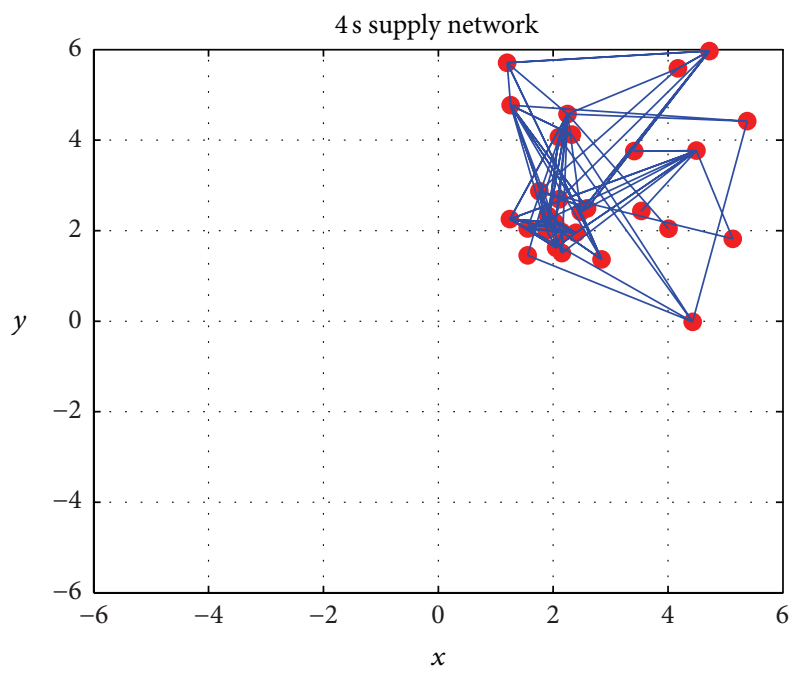

(c)

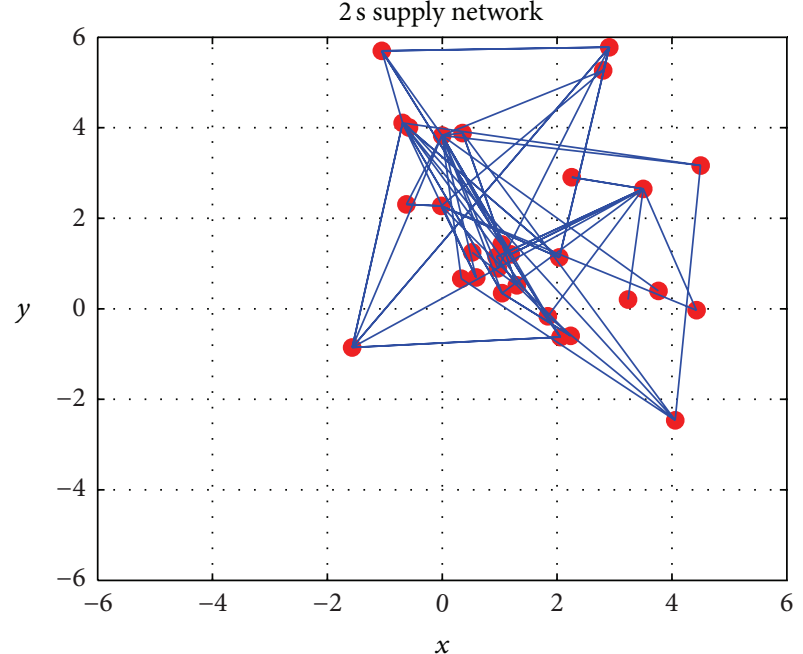

(b)

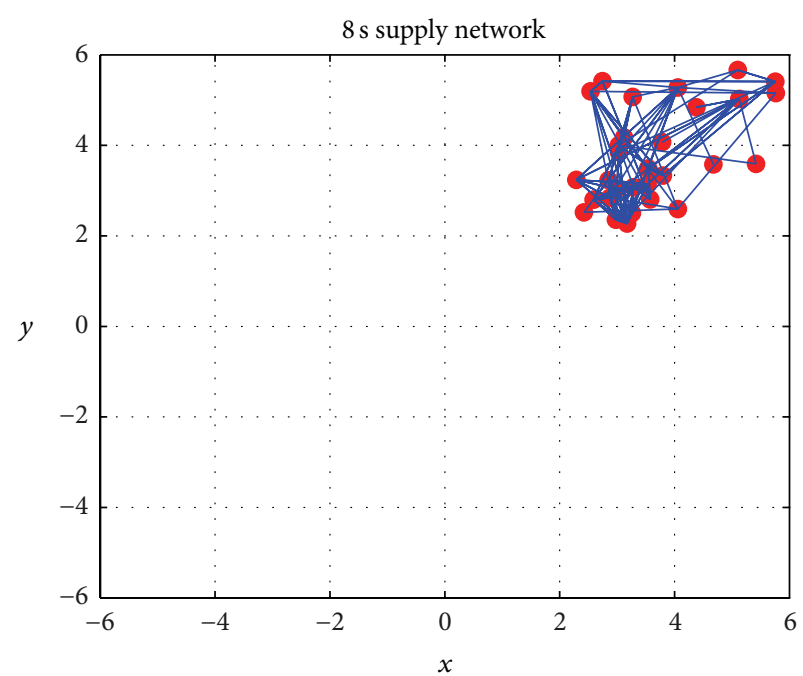

(d)

FIgURE 4: The emergence of supply chain combined effect.

The mean square error of acceleration, position, and velocity are, respectively, represented as $\sigma_{a}, \sigma_{x}$, and $\sigma_{v}$. Consider the following:

$$
\begin{gathered}
\sigma_{a}=\sqrt{\frac{1}{N} \sum_{i=1}^{N}\left\|a_{i}-\bar{a}\right\|^{2}}, \quad \sigma_{x}=\sqrt{\frac{1}{N} \sum_{i=1}^{N}\left\|x_{i}-\bar{x}\right\|^{2}}, \\
\sigma_{v}=\sqrt{\frac{1}{N} \sum_{i=1}^{N}\left\|v_{i}-\bar{v}\right\|^{2} .}
\end{gathered}
$$

Assume that (1), for any agent, $\left\|x_{i}-x_{j}\right\| \leq d$ and (2) the initial system resilience is $Q_{0}, \forall t>0, Q(t) \leq Q_{0}$.
The characteristic of function with potential energy $\psi\left(\left\|x_{i}-x_{j}\right\|\right) \geq \psi(\rho)$ is given as follows:

$$
\begin{gathered}
Q(t)=\frac{1}{2} \sum_{i=1}^{N}\left(U_{i}(t)+E_{i}(t)\right), \\
\sum_{i=1}^{N} c_{1}\left\|x_{i}-\bar{x}_{i}^{*}\right\|^{2}+\sum_{i=1}^{N} c_{2}\left\|x_{i}-\bar{x}\right\|^{2}+\sum_{i=1}^{N} \sum_{j=1, j \neq i} c_{4} \psi\left(\left\|x_{i}-x_{j}\right\|_{\sigma}\right) \\
+\sum_{i=1}^{N} c_{3}\left\|v_{i}-\bar{v}\right\|^{2} \leq 2 Q_{0}, \\
\sum_{i=1}^{N} \sum_{j=1, j \neq i} c_{4} \psi\left(\left\|x_{i}-x_{j}\right\|_{\sigma}\right) \geq c_{4} N(N-1) \psi(\rho),
\end{gathered}
$$




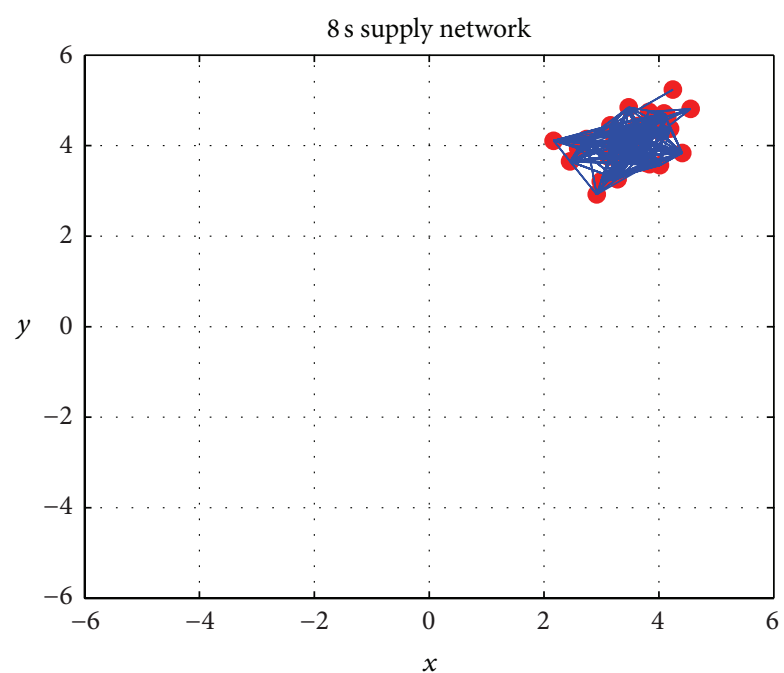

FIGURE 5: Evolution results of number 2.

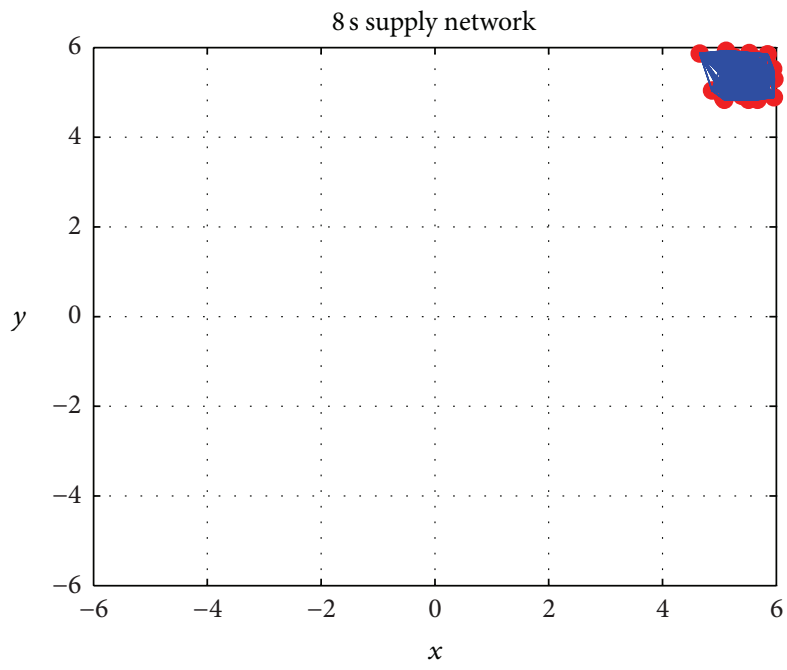

FIGURE 6: Evolution results of number 3.

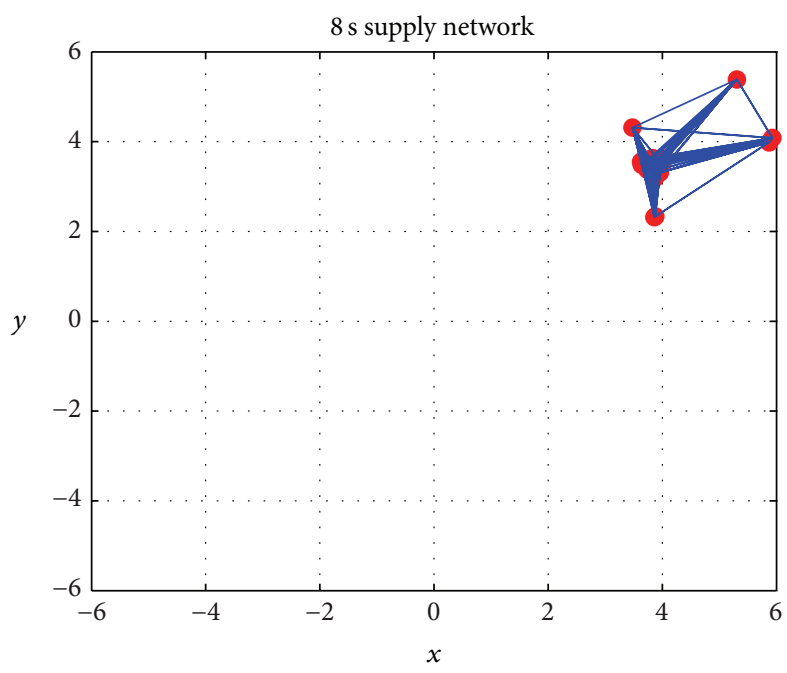

FIGURE 7: Evolution results of number 4.

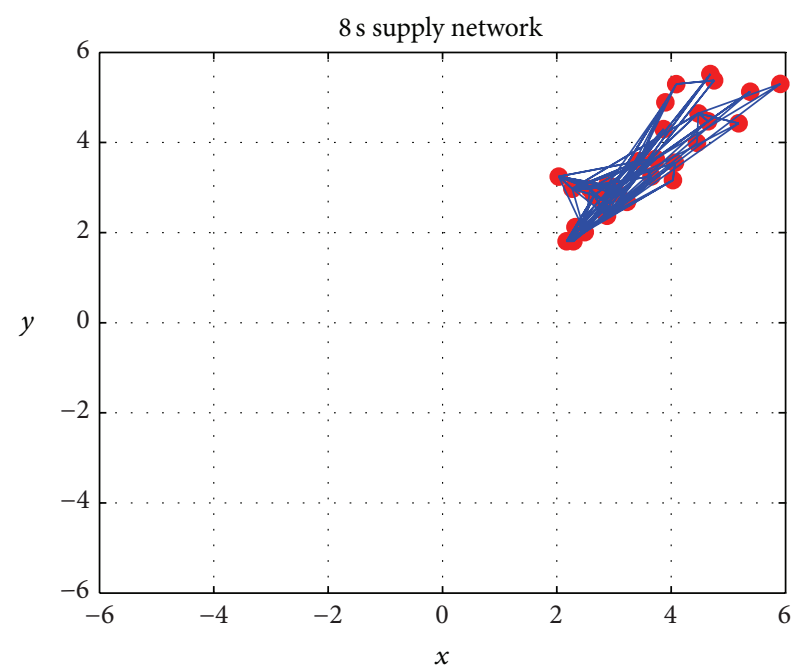

FIGURE 8: Evolution results of number 5.

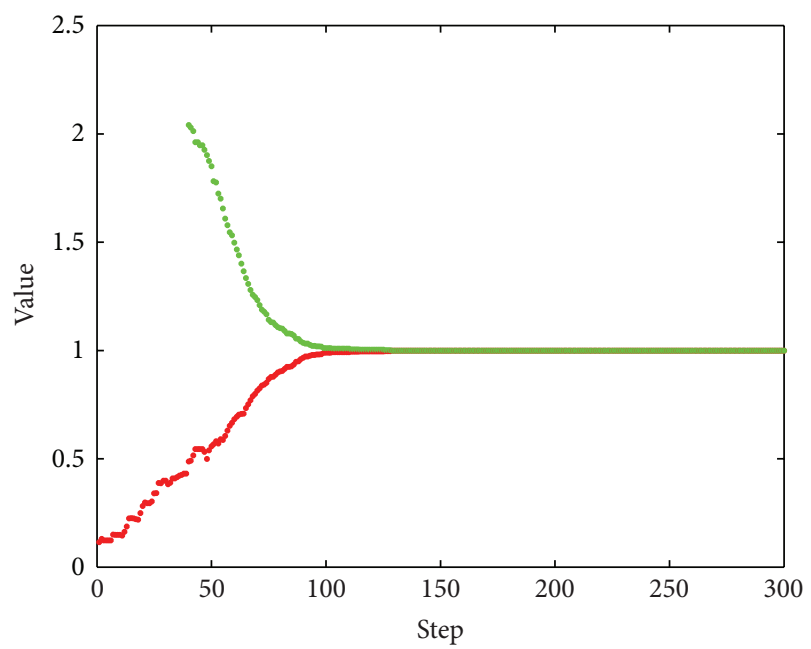

FIGURE 9: The emergence of connectivity and rate of information flow.

$$
\begin{aligned}
& \sum_{i=1}^{N} c_{1}\left\|x_{i}-\bar{x}_{i}^{*}\right\|^{2}+\sum_{i=1}^{N} c_{2}\left\|x_{i}-\bar{x}\right\|^{2}+\sum_{i=1}^{N} c_{3}\left\|v_{i}-\bar{v}\right\|^{2} \\
& \quad \leq 2 Q_{0}-c_{4} N(N-1) \psi(\rho) .
\end{aligned}
$$

Assume that $K=2 Q_{0}-c_{4} N(N-1) \psi(\rho)$ and

$$
\begin{array}{ll}
\sum_{i=1}^{N} c_{2}\left\|x_{i}-\bar{x}\right\|^{2} \leq K, & \sum_{i=1}^{N} c_{3}\left\|v_{i}-\bar{v}\right\|^{2} \leq K, \\
\sum_{i=1}^{N}\left\|x_{i}-\bar{x}\right\|^{2} \leq \frac{K}{c_{2}}, & \sum_{i=1}^{N}\left\|v_{i}-\bar{v}\right\|^{2} \leq \frac{K}{c_{3}},
\end{array}
$$




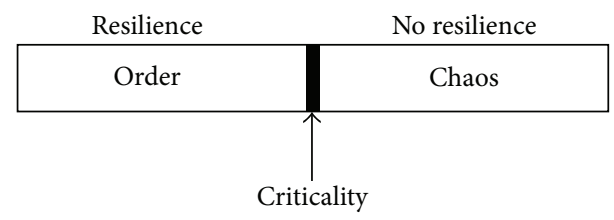

FIGURE 10: Self-organized criticality.

$$
\begin{gathered}
\sigma_{x}=\sqrt{\frac{1}{N} \sum_{i=1}^{N}\left\|x_{i}-\bar{x}\right\|^{2}} \leq \sqrt{\frac{K}{c_{2} N}} \\
\sigma_{v}=\sqrt{\frac{1}{N} \sum_{i=1}^{N}\left\|v_{i}-\bar{v}\right\|^{2}} \leq \sqrt{\frac{K}{c_{3} N}} .
\end{gathered}
$$

As shown in (14), the fluctuation of all agents' ability and status will stabilize within a certain range, and the specific range is related to the system initial state and its coefficient. The smaller the value is, the more consistent the agent behavior will be and the more orderly the system will become. Small perturbation will not have a devastating impact on the supply chain, and the system will recover during the dynamic self-organizing process. In the case of small random disturbance, we can constrain the overall behavior of the supply network through setting the value of the initial state and the control parameters.

5.3. Supply Chain Resilience and SOC Emergence. Self-organized criticality can be considered as a characteristic state of criticality which is formed by self-organization in a long transient period at the border of stability and chaos, as shown in Figure 10.

Figure 11 shows the resilience index of evolution in number 1, which is used to display the effect of supply chain resilience. Figure 12 shows the resilience index of evolution in number 1 when the coefficient of Wander $U$ is larger $\left(V_{5}=20\right)$; namely, the random disturbance is very large, in which the resilience disappears. Figure 11 is an orderly part of Figure 10, while Figure 12 is the other part of Figure 10, and there will be a critical value. The same characteristic is shown in Figures 13 and 14, which corresponds to the situation in number 5 .

The simulation verifies the essence of supply chain resilience that we have described in Section 3, in which the supply chain resilience is the macroproperty that generates from microindividual "self-organization." In the process of evolution, supply chain system owns a stable state, which is gradually formed through each enterprise in the supply chain constantly adapting to the internal and external environment, and the dependence on the environment forms contractual relationships between enterprises. Thus, it ensures that the parameters of enterprises can be far away from mutation and obtain a relatively stable operational condition. This stable state is within the range of critical value. Because the random variable $V_{5}$ is added from the outside of system and the kinetic energy of each agent is transformed into potential energy through self-organizing interactions, the agent with stronger potential energy will have stronger self-organizing ability,

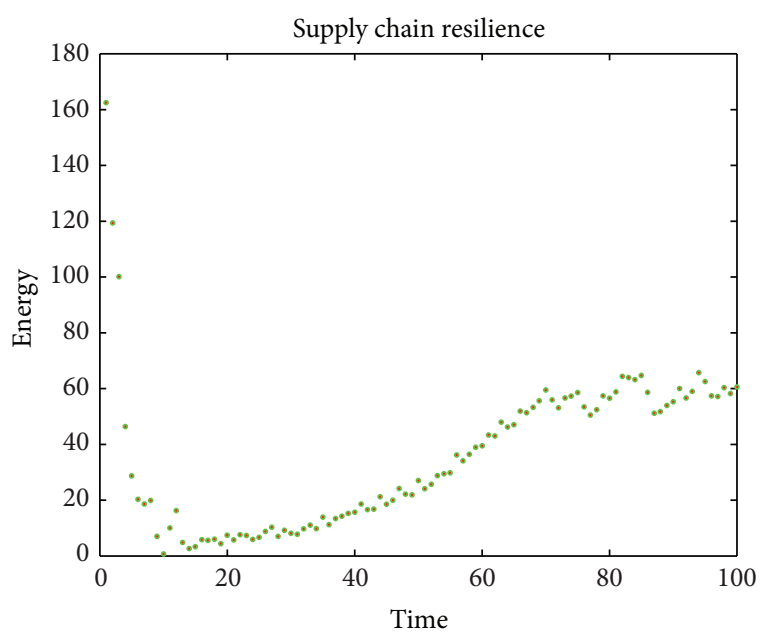

FIGURE 11: There is resilience within SOC/number 1.

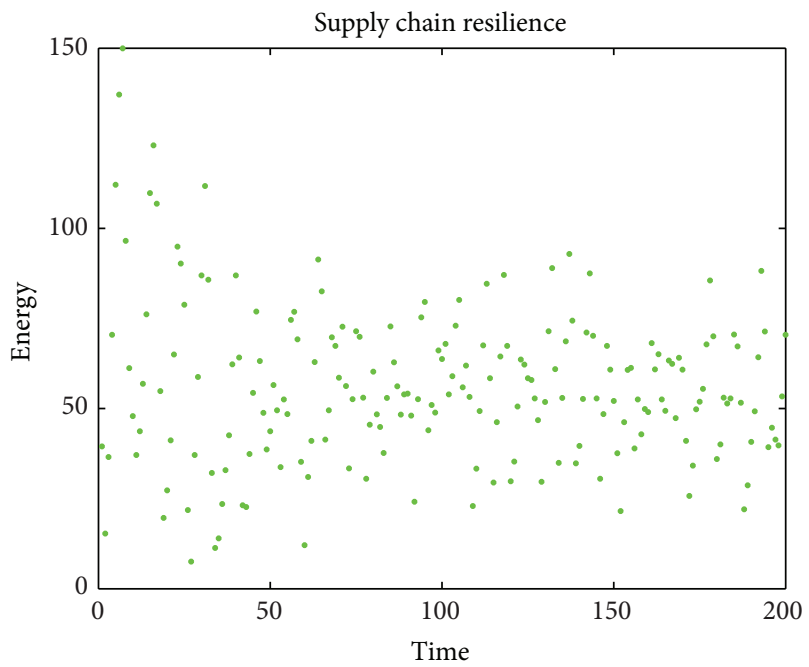

FIGURE 12: There is no resilience at SOC/number 1.

which can further enhance the agent kinetic energy. Therefore, there is energy flow within whole supply chain system. The reason why the critical point can be achieved is because the energy is inputted from the outside of system in the form of random variable $V_{5}$. The impact of fluctuations continues to gather, eventually leading to a large-scale collapse.

In order to further verify the above conclusion, we conduct a test based on the data of chemical integrated supply network in the literature of [28]. The network organization focuses on natural gas and chemical engineering production and owns a cooperative system of up, middle, and down product chain with comprehensive supporting enterprises, including 40 functional units, in which 1-19 are the core production units, 20 and 21 are raw materials processing units, and 22-40 are storage and transportation units of semifinished products and finished products. The initial network is shown in Figure 15. The parameters of number 1 are used in this case. The same characteristics are shown in Figures 16 and 17, which correspond to the situation in the case. 


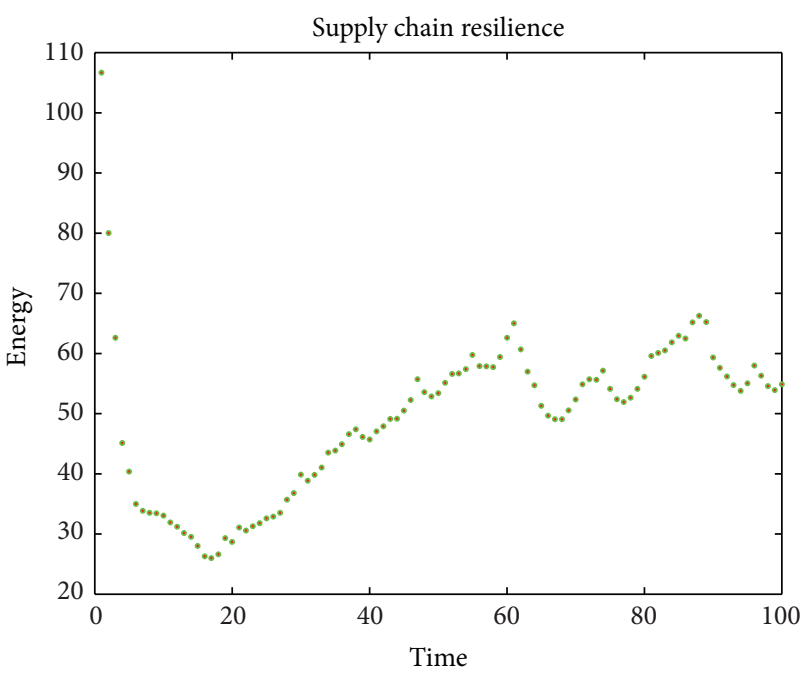

FIGURE 13: There is resilience within SOC/number 5.

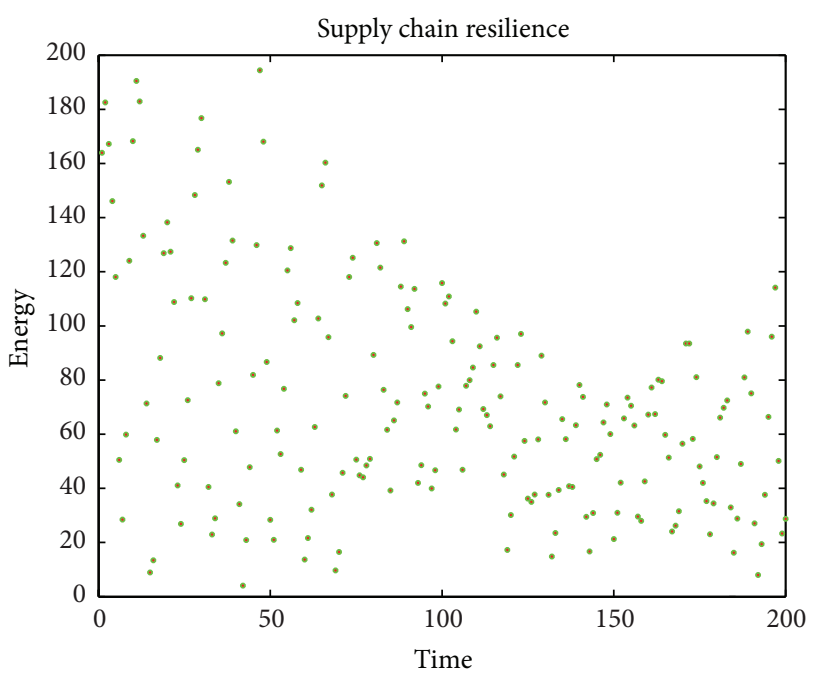

FIGURE 14: There is no resilience at SOC/number 5.

In fact, the disaster is caused by many small highly decentralized decisions, which gather together in a pace that is difficult to detect. Every decision is too tiny to look harmful, but they can slowly erode the resilience of the system. When making decisions, none of the enterprises can understand the impact that their behavior brings to the entire supply chain and, unknowingly, the system becomes more vulnerable. Every enterprise takes rational action itself within local range, which can bring significant individual interest. As time goes on, these decisions slowly change the rules of the system. Since the previous choices may not be punished, each enterprise tends to choose behavior with more interest, which also brings higher risk. As a whole, the supply chain system slowly approaches the possible disaster, showing selforganized criticality.

From resilience to no-resilience, it will cross a critical point. And the critical point for the supply chain system also frequently changes. It needs to balance between interest and
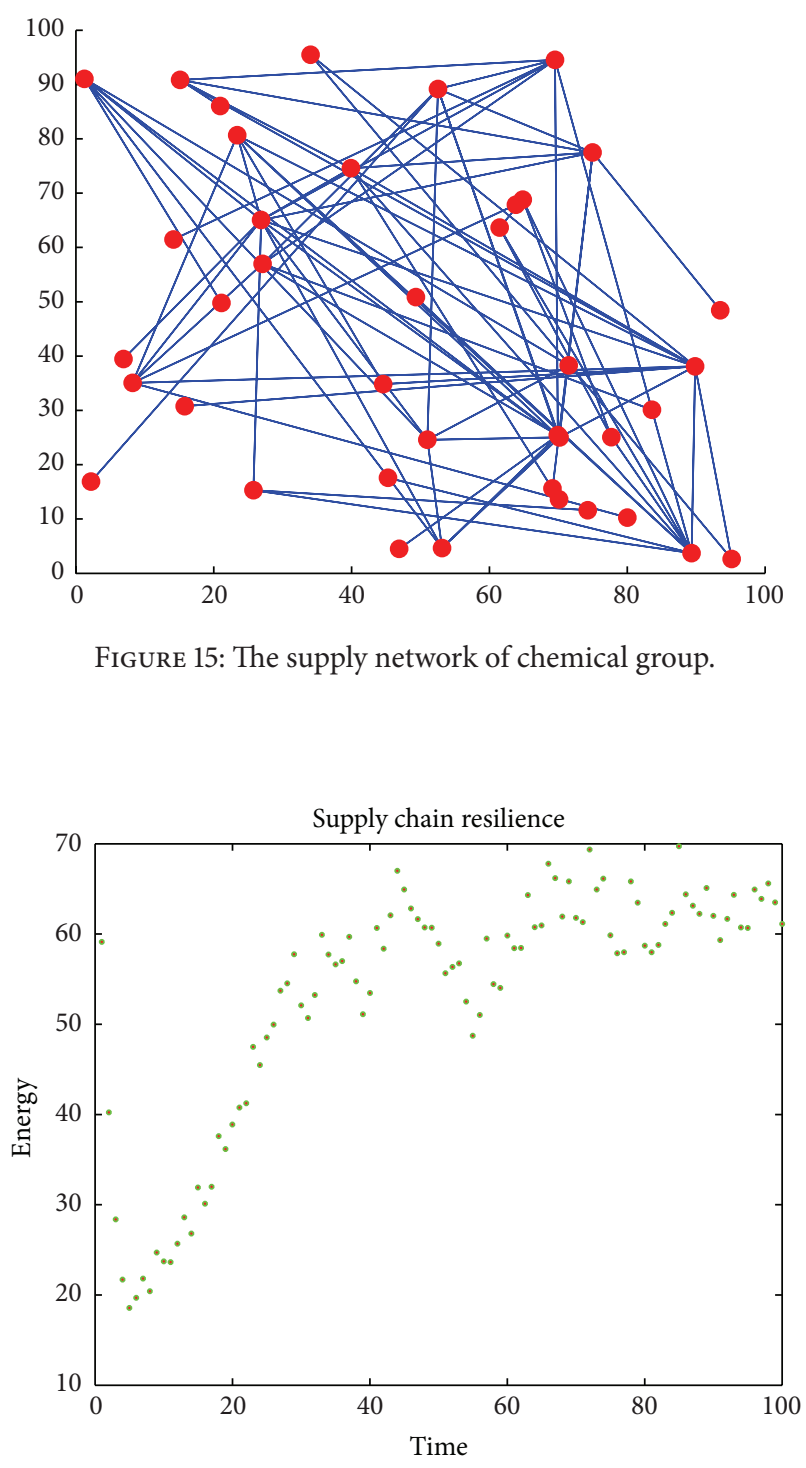

FIgURE 16: There is resilience within SOC/chemical.

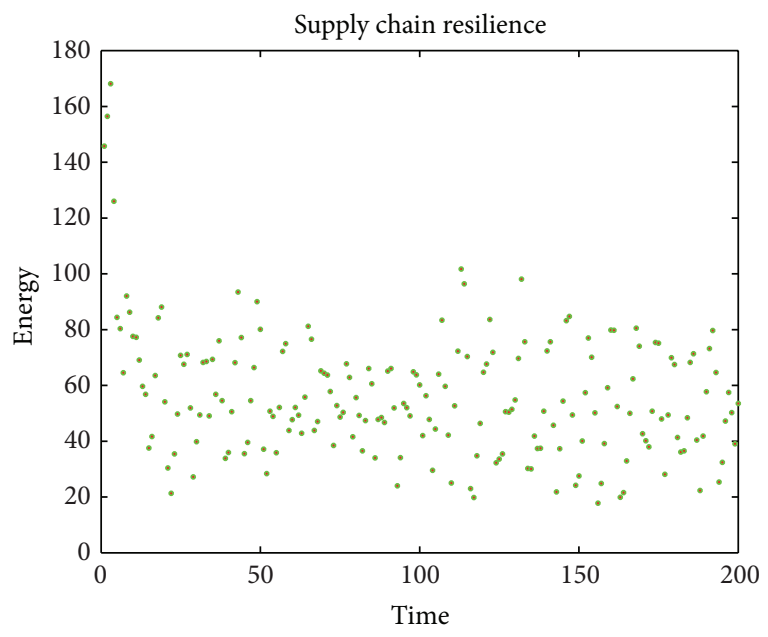

FIgURE 17: There is no resilience at SOC/chemical. 
risk to make choice between the efficient but vulnerable and the inefficient but robust. To control supply chain resilience, it needs to choose a good balance between them.

\section{Conclusion}

Based on our previous study [11], we map the supply chain system into MAS system through the comparison of supply chain's microscopic individual behavior and its macroscopic property. Through taking the enterprise as agent and designing the local fitness function, neighborhood structure, and interaction rules that are suitable for supply chain system, we find that the macroscopic property of supply chain system generates from its microscopic behavior and the supply chain resilience generates by local self-organizing behavior. Besides, we also study the resilience of supply chain and its self-organized critical characteristic. And we get some meaningful conclusions as follows.

(1) We find the combined effect in the evolution of supply chain through the simulation, which is similar to the actual situation. The connectivity increases as the clustering coefficient increases, and the rate of information flow increases as the average path length decreases. Through closer and closer cooperation and communication of information between enterprises, the degree of homogeneity in the supply chain enterprise becomes higher and higher.

(2) Through analyzing the statistical properties of supply chain resilience model, it is shown that resilience is controlled by parameters of agents, such as the executive ability and the scope of choosing partners, which have a positive effect on the combined effect. Managers can control the supply chain within the resilient range by controlling the behavior of the enterprise. Within the range, supply chain can continuously eliminate effects and release energy due to its self-organizing behavior, to slow down the occurrence of large-scale collapses events.

(3) We find that there exists SOC characteristic in supply chain resilience through the simulation, and the supply chain is a robust but vulnerable system. Most of the time, supply chain stays in a stable state due to its resilience. But when it crosses the selforganization critical point, the supply chain will out of control and an avalanche event may occur by small perturbations, which means that the supply chain is extremely vulnerable in this environment. Managers will find the proper balance between the efficiency and risk by controlling the behavior of the enterprises.

To enhance the supply chain resilience, we should pay close attention to self-organizing ability of each enterprise. As the supply chain has characteristic of self-organized criticality, supply chain should be prevented from crossing self-organized critical point and should be controlled. To control supply chain resilience, we can choose a good balance between the efficient but vulnerable and the inefficient but robust. This study provides theoretical guidance to optimize the resilience of the supply chain through local control. In the future, we will study the factors that affect the self-organized critical point and how to prevent the supply chain from crossing self-organized critical point.

\section{Conflict of Interests}

The authors declare that there is no conflict of interests regarding the publication of this paper.

\section{Acknowledgments}

This project is supported by the National Natural Science Foundation of China (no. 71171089) and the Natural Science Foundation of Zhejiang Province of China (no. LY14F020023).

\section{References}

[1] X. Y. Huang and N. N. Yan, "Research progress on supply chain robustness," Chinese Journal of Management, vol. 4, no. 4, pp. 521-528, 2007.

[2] C. S. Holling, "Resilience and stability of ecological systems," Annual Review of Ecology and Systematics, vol. 4, pp. 1-23, 1973.

[3] C. Folke, S. Carpenter, T. Elmqvist, L. Gunderson, C. S. Holling, and B. Walker, "Resilience and sustainable development: building adaptive capacity in a world of transformations," Ambio, vol. 31, no. 5, pp. 437-440, 2002.

[4] W. N. Adger, "Social and ecological resilience: are they related?" Progress in Human Geography, vol. 24, no. 3, pp. 347-364, 2000.

[5] G. A. Bonanno, "Loss, trauma, and human resilience: have we underestimated the human capacity to thrive after extremely aversive events?" The American Psychologist, vol. 59, no. 1, pp. 20-28, 2004.

[6] D. S. Callaway, M. E. J. Newman, S. H. Strogatz, and D. J. Watts, "Network robustness and fragility: percolation on random graphs," Physical Review Letters, vol. 85, no. 25, pp. 5468-5471, 2000.

[7] R. Starr, J. Newfrock, and M. Delurey, "Enterprise resilience: managing risk in the networked economy," Strategy and Business, no. 30, pp. 70-79, 2003.

[8] Y. Sheffi, "Building a resilient supply chain," Harvard Business Review, vol. 1, no. 8, pp. 1-4, 2005.

[9] P. P. Datta, M. Christopher, and P. Allen, "Agent-based modelling of complex production/distribution systems to improve resilience," International Journal of Logistics Research and Applications: A Leading Journal of Supply Chain Management, vol. 10, no. 3, pp. 187-203, 2007.

[10] S. Ratick, B. Meacham, and Y. Aoyama, "Locating backup facilities to enhance supply chain disaster resilience," Growth and Change, vol. 39, no. 4, pp. 642-666, 2008.

[11] C. Colicchia, F. Dallari, and M. Melacini, "Increasing supply chain resilience in a global sourcing context," Production Planning and Control: The Management of Operations, vol. 21, no. 7, pp. 680-694, 2010.

[12] K. Zhao, A. Kumar, T. P. Harrison, and J. Yen, "Analyzing the resilience of complex supply network topologies against random and targeted Disruptions," IEEE Systems Journal, vol. 5, no. 1, pp. 28-39, 2011. 
[13] L. Geng, R. B. Xiao, and S. S. Xie, "Research on self-organization in resilient recovery of cluster supply chains," Discrete Dynamics in Nature and Society, vol. 2013, Article ID 758967, 11 pages, 2013.

[14] T. J. Pettit, K. L. Croxton, and J. Fiksel, "Ensuring supply chain resilience: development and implementation of an assessment tool," Journal of Business Logistics, vol. 34, no. 1, pp. 46-76, 2013.

[15] R. Francis and B. Bekera, "A metric and frameworks for resilience analysis of engineered and infrastructure systems," Reliability Engineering and System Safety, vol. 121, pp. 90-103, 2014.

[16] J. G. Liu, G. W. Shi, B. Lu et al., "The three factor model of the supply chain elasticity," Chinese Journal of Management Science, vol. 20, pp. 528-535, 2012.

[17] P. Bak, "How nature works: the science of self-organized criticality," Nature, vol. 383, no. 6603, pp. 772-773, 1996.

[18] P. Bak, How Nature Works, Oxford University Press, Oxford, UK, 1997.

[19] J. P. Da Cruz and P. G. Lind, "Self-organized criticality in a network of economic agents with finite consumption," Physica A: Statistical Mechanics and its Applications, vol. 391, no. 4, pp. 1445-1452, 2012.

[20] J. L. Guo, "Bilateral power-law distribution model of supply chain networks," Acta Physica Sinica, vol. 55, no. 8, pp. 39163921, 2006 (Chinese).

[21] X. Gabaix, P. Gopikrishnan, V. Plerou, and H. E. Stanley, "A theory of power-law distributions in financial market fluctuations," Nature, vol. 423, no. 6937, pp. 267-270, 2003.

[22] A. Clauset, C. R. Shalizi, and M. E. . Newman, "Power-law distributions in empirical data," SIAM Review, vol. 51, no. 4, pp. 661-703, 2009.

[23] L. Lu and G. Wang, "A study on multi-agent supply chain framework based on network economy," Computers \& Industrial Engineering, vol. 54, no. 2, pp. 288-300, 2008.

[24] A. Smith and J. M. Vidal, "A practical multiagent model for resilience in commercial supply networks," Agent-Mediated Electronic Commerce, vol. 2010, article 169, 2010.

[25] Z. Huang and R. Xiao, "An emergent computation approach to the problem of polygon layout with performance constraints," Physica A: Statistical Mechanics and Its Applications, vol. 392, no. 20, pp. 5074-5088, 2013.

[26] Y. Wu, J. Su, H. Tang, and H. Tianfield, "Analysis of the emergence in swarm model based on largest Lyapunov exponent," Mathematical Problems in Engineering, vol. 2011, Article ID 745257, 21 pages, 2011.

[27] http://www.cninfo.com.cn/finalpage/2012-04-21/60870836 .PDF.

[28] F. Zhang, Y. Yang, J. Jia, and J. Wang, "Correlation analysis of failure modes and vulnerability in collaborative production networked organizations," Computer Integrated Manufacturing Systems, CIMS, vol. 18, no. 6, pp. 1236-1245, 2012 (Chinese). 


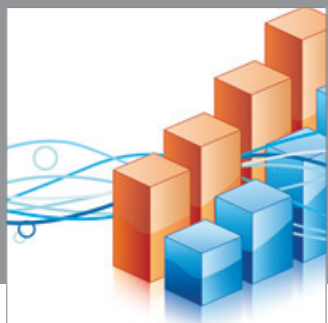

Advances in

Operations Research

mansans

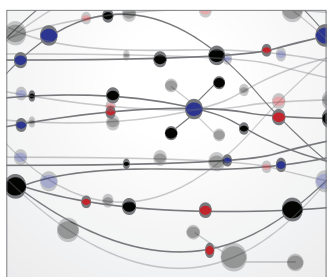

The Scientific World Journal
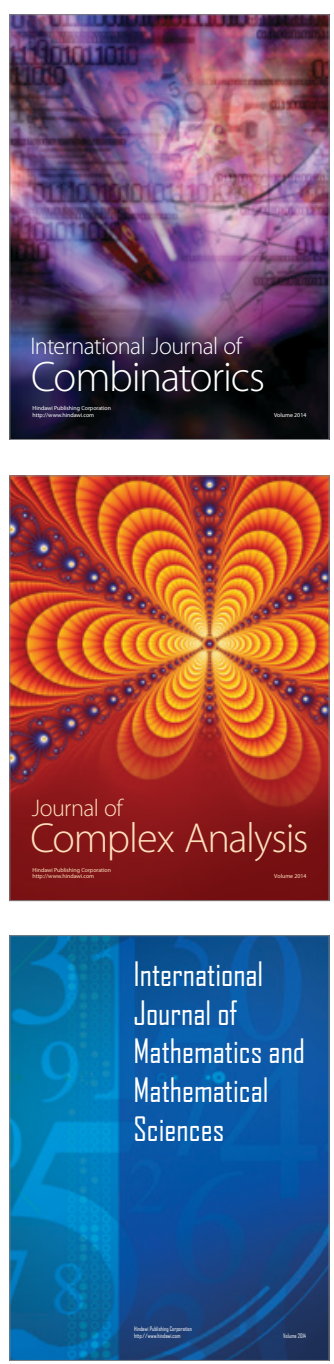
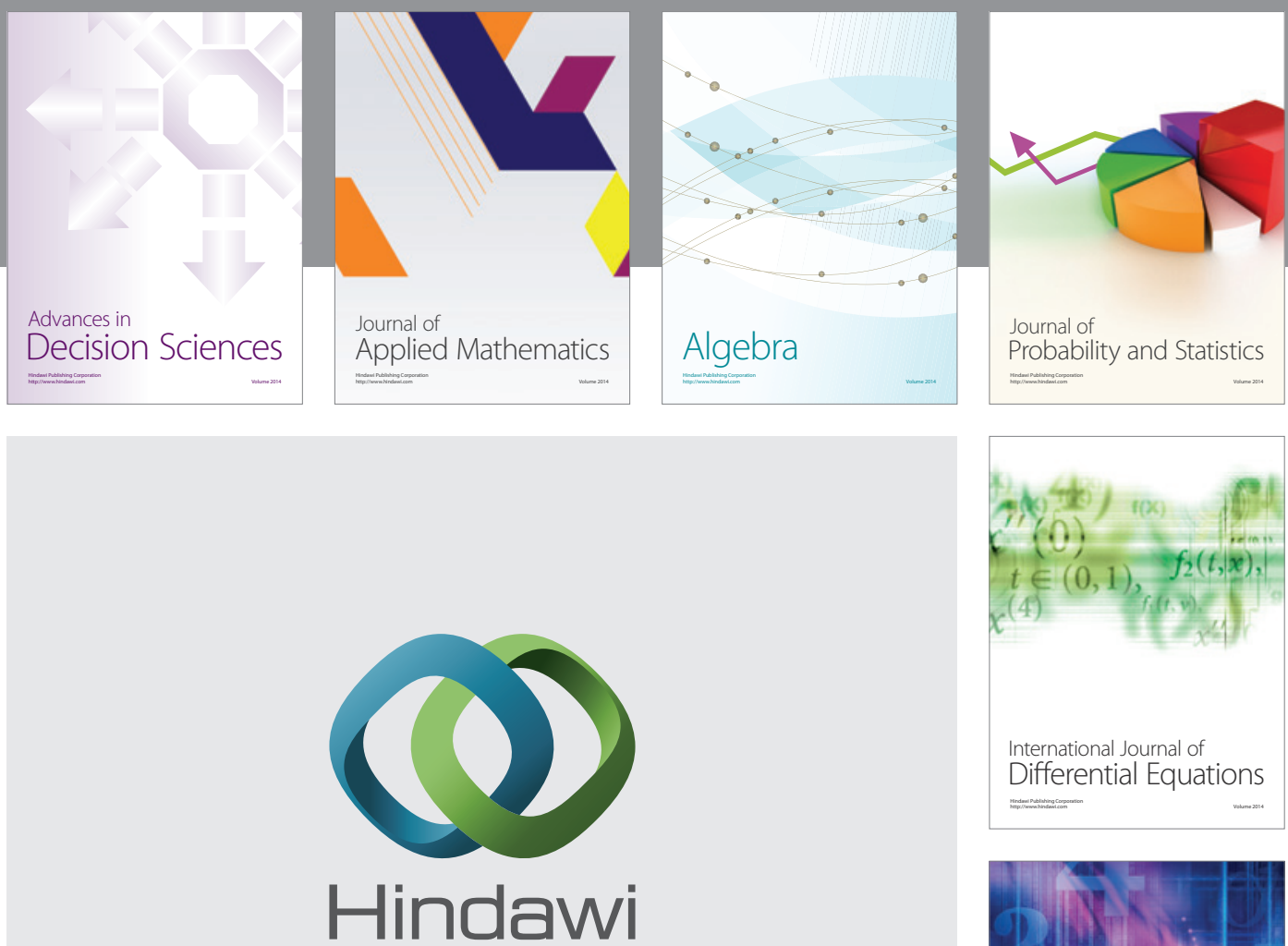

Submit your manuscripts at http://www.hindawi.com
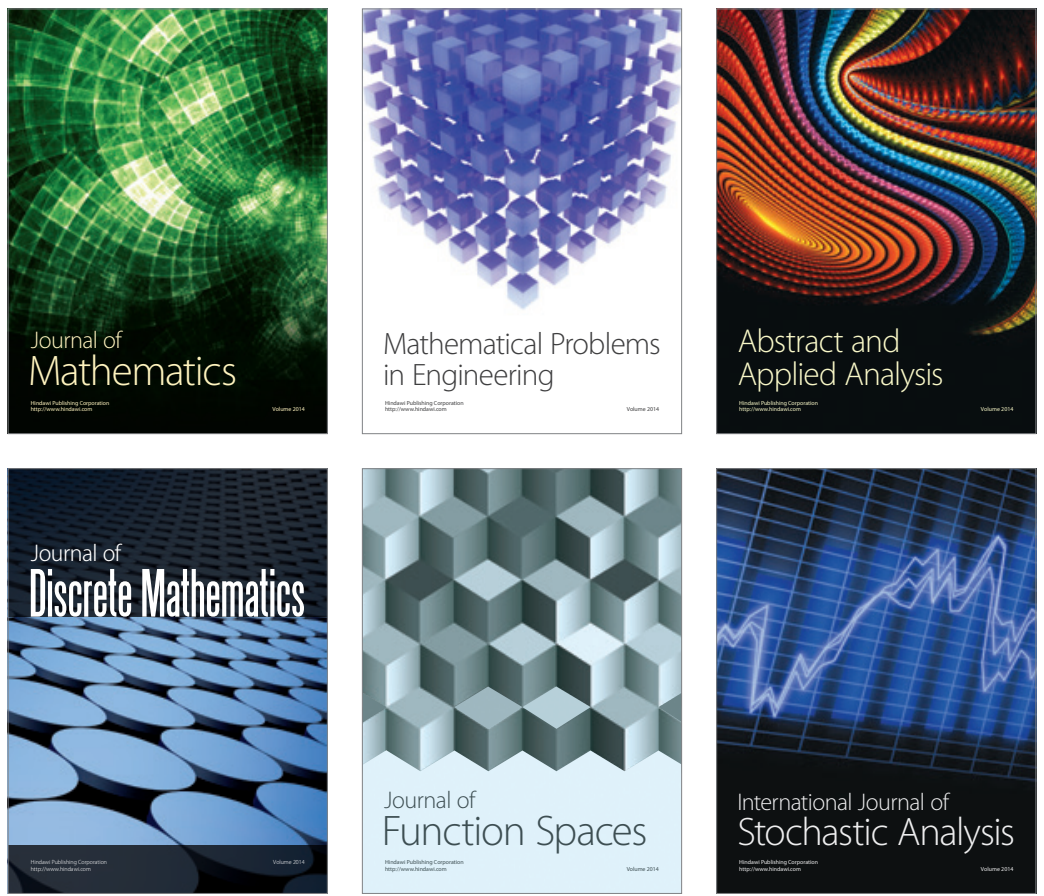

Journal of

Function Spaces

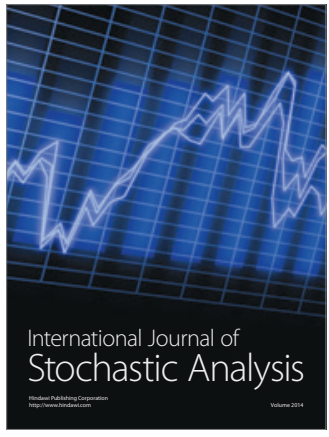

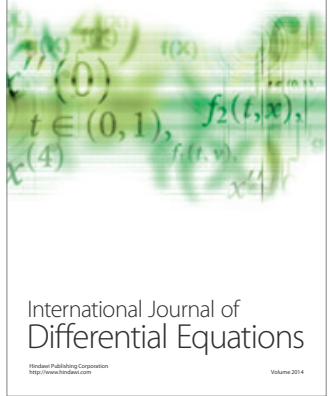
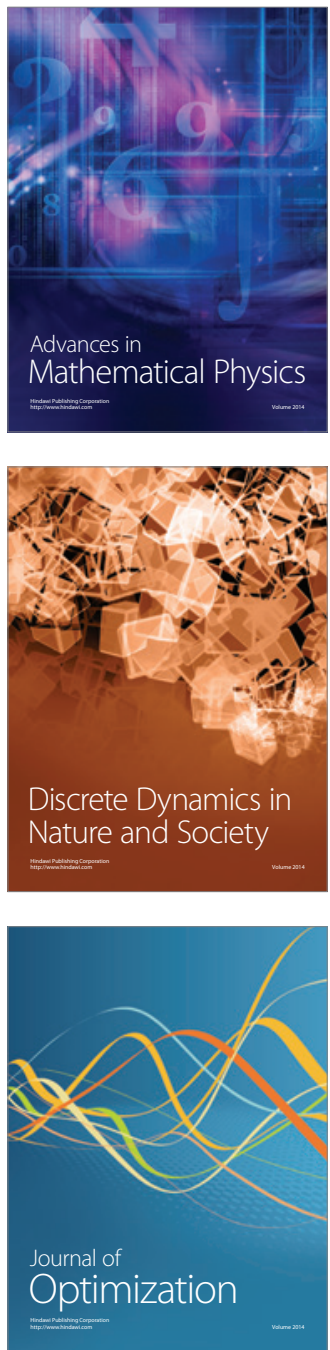